

\section{EXPEDIENTE}

Universidade do Estado do Rio de Janeiro - UERJ

Instituto de Estudos Sociais e Políticos - IESP

CADERNOS DE ESTUdOS SOCIAIS E POLÍTICOS www.e-publicacoes.uerj.br/index.php/CESP

\section{COMITÉ EDITORIAL}

Anna Carolina Venturini, IESP-UERJ

Felipe Munhoz de Albuquerque, IESP-UERJ

Leonardo Nóbrega da Silva, IESP-UERJ

Marcelo Borel, IESP-UERJ

Marcia Rangel Candido, IESP-UERJ

Marina Rute Pacheco, IESP-UERJ

Mariane Silva Reghim, IESP-UERJ

Natália Leão, IESP-UERJ

Paulo Joaquim Da Silva Rodrigues, IESP-UERJ

Raul Nunes de Oliveira, IESP-UERJ

\section{CAPA, LAYOUT E DIAGRAMAÇÃO}

Marcia Rangel Candido

Raul Nunes de Oliveira 


\section{Apresentação}

Mariane Silva Reghim

\section{Dossiê}

É Possível Fazer Ciências Sociais sem uma Análise Crítica das

Categorias de Diferenciação? Uma Proposição Feminista

Natália Corazza Padovani

As Perspectivas Teóricas Queer e o Uso Cotidiano da Língua

Portuguesa

Helza Ricarte Lanz e Juliane Noack Napoles

Raça e Violência Sexual: Âmbito de Aplicação da Vitimodogmática?

Amanda Bessoni Boudoux Salgado e José Roberto Macri Jr.

What Happened with "What Happened, Miss Simone?"? - Assistindo ao Documentário Pela Ótica do Feminismo Negro

Rafael Pinto Ferreira de Queiroz

O Racismo Institucional no Brasil: Contribuições de Louis Althusser para o Debate

\section{Artigos}

O Voto Econômico na América Latina entre 2004 - 2012: Avaliação da Economia e do Desempenho do Governo em Políticas Públicas e de Combate à Corrupção

Flávia Bozza Martins

Eleições Presidenciais de 2014: Reflexões sobre o Capital Político e a

Capitalização de Votos de Marina Silva

Bruno Fonseca Gurão e Mirna Tonus

\section{Resenha}

Neoliberalismo Desde Baixo, Pós-Fordismo Periférico e Cálculos Emancipatórios

Igor Peres

Sobre Autogestão nas Fábricas Recuperadas no Brasil: (R)Existindo no Mercado 


\title{
É Possível Fazer Ciências Sociais sem uma Análise Crítica das Categorias de Diferenciação? Uma Proposição Feminista ${ }^{1}$
}

\author{
Is It Possible to Do Social Science Without a Critical Analysis of Differentiation Categories? A Feminist \\ Proposition.
}

Natália Corazza Padovani ${ }^{2}$

\section{RESUMO}

Por meio da retomada de literaturas e temas caros para o feminismo e para as teorias pós-coloniais, o presente ensaio teórico disserta sobre a impossibilidade de fazer Ciências Sociais sem uma análise das categorias de diferenciação e suas interseccionalidades. Ao longo do texto, e com base na revisão de um cabedal crítico aos "universalismos transparentes", sob os quais repousou (e repousa) parte significativa da produção acadêmica das Ciências Humanas, o ensaio indaga as "fronteiras" que separam corpos e epistemologias, intimidade e política, por meio de violentas assimetrias de poder.

PALAVRAS CHAVE: Categorias de diferenciação, interseccionalidades, feminismos.

\begin{abstract}
Through the resumption of literature and themes dear to feminism and postcolonial theories, the present theoretical essay discusses the impossibility of doing Social Sciences without an analysis of the categories of differentiation and their intersectionalities. Throughout the text, and based on the revision of a critical material to the "transparent universalisms" under which a significant part of the academic production of the Human Sciences rests, the essay investigates the "frontiers" that separate bodies and epistemologies, intimacy and politics, through violent asymmetries of power.
\end{abstract}

KEYWORDS: Categories of differentiation, intersectionalities, feminisms.

1 Gostaria de agradecer à Revista Cadernos de Estudos Sociais e Políticos pela oportunidade de sistematizar, nas linhas que seguem, parte de material teórico que venho elaborando por meio de disciplinas e notas pessoais desde 2013. Agradeço principalmente ao editor, Macelo Borel, pelo convite e pela imensa paciência nos prazos. Agradeço ainda a Adriana Piscitelli, Carolina Branco e Larissa Nadai, parceiras com as quais ministrei as disciplinas "Pensamento pós-colonial, decolonial e feminismos", em 2017, e "Estudos de Gênero e Estado", em 2018. O ensaio propositivo que segue, certamente tem muito de nossas conversas. Agradeço por isso, ainda, aos participantes, "alunas e alunos", das duas disciplinas, bem como do Seminário "Seminário Livre de Pesquisa sobre Feminismos, nações e fronteiras", promovido pelo Departamento de Sociologia da UECE. Em nossas trocas de saberes aprendi e aprendo todos os dias. Por fim, agradeço a Cilmara Veiga pela leitura delicada de sempre. A responsabilidade pelos posicionamentos e proposições expostas neste artigo é completamente minha.

2 Pesquisadora do Núcleo de Estudos de Gênero Pagu/UNICAMP. E-mail: nataliacorazzapadovani@gmail.com 


\section{INTRODUÇÃO}

Em um ensaio bibliográfico sobre "marcadores sociais da diferença" e processos de produção social das desigualdades, Laura Moutinho (2014) formula o seguinte questionamento: “Como nos tornamos 'nós'? Como nos tornamos 'eles'? Como alguns se tornam 'nós' e outros ‘eles'?” (Moutinho, 2014: 203). A indagação com que Moutinho abre seu texto é basal para as Ciências Humanas e Sociais. Análises e entomologias sobre as diferenças (e desigualdades) entre "nós" e "outros", bem como sobre as "especificidades" das "populações" e/ou "indivíduos" (Foucault, 1979) é substrato das inquietações que impulsionaram a produção da epistemologia ocidental colonial (Monteiro, 2000; Oliveira, 2016).

De mesmo (ou de outro) modo, as provocações subversivas a essa epistemologia feitas por autores "pós-coloniais"3 (Said, 2007; Spivak, 2010; Mohanty, 1986), também se voltam para como geopolíticas de saber vêm produzindo noções de "nós" e "eles". Noções determinantes das relações de poder e práticas de governamentalidade que implementam políticas de saber, de guerra e de mercado, por exemplo (Corrêa, 2003; Abu-Lughod, 2002; Grewal, 2005). Parte significativa do arsenal teórico considerado canônico no desenvolvimento das Ciências Sociais tem, entretanto, ignorado reiteradamente que categorizações de nós e eles foram e são feitas por meio de dispositivos de poder que produzem diferenças e assimetrias entre sujeitos localizados nas relações como "nós" e "aqueles" (muitas vezes indesejados) "outros".

Já argumentei, em distintos momentos (Padovani, 2016a, 2016b e 2017) que parcela significativa das produções acadêmicas sobre "prisões" no Brasil, principalmente quando se referem a trabalhos etnográficos desenvolvidos desde unidades masculinas, ignoram em suas análises que relações de poder são indissociáveis do modo como sujeitos são categorizações diferente e desigualmente desde atributos de gênero, raça e classe. Argumento o qual nem de longe eu inauguro. Antes, Angela Davis (2003) tem já há muitos anos insistido que "gênero é estruturante do sistema prisional".

As análises persistentes de Angela Davis relacionam-se às famosas colocações publicadas em artigo por Joan Scott, em 1986. Nesse, a autora defendia ser gênero categoria central para as

3 Sobre a crítica pós-colonial, ou melhor, sobre uma análise crítica aos próprios usos e noções do termo “pós-colonial", ver: McClintock, 2010: 27-40. 
análises históricas dos processos políticos que produzem, inclusive, compreensões de nação e de nacionalidade. Com essa formulação, Joan Scott dissertava sobre ser gênero não uma categoria que permitia descrever "experiências masculinas" e "experiências femininas" na história. Antes, "gênero", não pensado como sinônimo de "mulher" pela autora, era categoria fundamental para a compreensão e produção da análise histórica. Nesse registro, Scott desenvolveu seu argumento não localizando as mulheres em uma história específica (ou em uma prisão específica), mas antes propondo esmiuçar como relações de gênero, desde atributos de "masculinidade e feminilidade", foram sendo utilizadas literal ou analogicamente na teoria política para justificar ou criticar reinados ou sistemas de governo. Os exemplos que fundamentam os argumentos de Joan Scott seguem em inúmeros desdobramentos descritivos. Mas o que importa chamar atenção aqui é que, para a autora, gênero é a forma primária de todas as relações de poder. Relações que produzem "homens e mulheres" como categorias transbordantes de efeitos de naturalização e fixação mesmo que estas sejam vazias de qualquer ontologia biológica ou natural. Podemos dizer que, para Scott gênero é, portanto, aparato linguístico por meio do qual os sujeitos produzem e se relacionam com a lei. O aparato linguístico por meio do qual guerras e fronteiras entre estados-nação são feitas e analisadas através da história.

Como veremos, foi sobre a consideração de ser "gênero forma primária de todas as relações de poder" que recaíram as críticas de autoras feministas negras e do terceiro mundo às análises propostas por Joan Scott. Mais do que contestar ser "gênero" categoria de diferenciação ordenadora do léxico por meio do qual são produzidas relações de poder, autoras feministas negras pós-coloniais e transnacionais (Gonzalez, 1988a; McClintock, 2010; Brah, 2011; Mohanty, 1984) vão levar os argumentos de Scott para as arenas das interseccionalidades, demonstrando como o aparato linguístico do gênero não pode ser compreendido em separado dos aparatos linguísticos que localizam sujeitos, populações e nações desde assimetrias de "nós e eles", atravessadas pelas diferenciações de raça e classe.

O presente ensaio teórico propõe dissertar sobre esse aparato linguístico que é produzido por e produz relações de poder em arenas de afeto públicas, nacionais e transnacionais. O presente ensaio teórico não propõe argumentar sobre a importância das categorizações de diferenciação para a produção das Ciências Sociais. Antes, questiona a viabilidade de produções científicas e acadêmicas não levarem em conta relações de poder, de sujeição e de autoria como seus constructos epistemológicos. 


\section{SOBRE AS “OUTRAS” QUE (NÃO) SOMOS "NÓS”: EPISTEMOLOGIA(S) FEMINISTA E A “MULHER"}

Autoras e autores feministas negras e negros, ou periféricas/os frente às assimetrias de produção de saber de seus contextos sócio-históricos, vêm, desde muitas décadas, empreendendo esforços em visibilizar que categorizações como "nós" e "outros" são forjadas socialmente em diferenças produzidas - ao mesmo tempo em que corporificadas - nas relações de poder assimétricas. Como uma das muitas célebres passagens da escrita de Simone de Beauvoir (1970) ironiza, apenas uma mulher teria a ideia de escrever um livro que questionasse, ou propusesse analisar, a semântica por meio da qual se produz o "segundo sexo", o sexo "outro". Um livro que propusesse questionar o que é uma mulher. Afinal, provoca a autora francesa, ser homem é o natural genérico que prescinde de qualquer explicação. Ser homem é ser o "universal”, enquanto ser "mulher é ser o seu outro específico" (Beauvoir, 1970: 9).

Anteriormente à Beauvoir, outra autora, mulher branca e europeia, já havia proposto ácidas indagações sobre a produção ficcional do "sujeito outro" mulher. Em 1929, Virginia Woolf publicou o livro "Um teto todo seu". ${ }^{4}$ No texto, a autora britânica é sarcástica ao subscrever as formas como ensaios ficcionais, romances e artigos naturistas que ela consultava na biblioteca do

4 Acionar a autora Virginia Woolf, aqui, não é um ato despropositado. Aliás, o uso de nenhum corpus de conhecimento é despropositado ou decorrente da "objetividade" científica. No que tange ao acionamento da escrita de Virginia Woolf, neste ensaio, cabe destacar que o mesmo pretende ser uma singela homenagem à professora Mariza Corrêa (1945-2016). Antropóloga da Universidade Estadual de Campinas, fundadora do Núcleo de Estudos de Gênero Pagu, do qual hoje faço parte, estudiosa da produção das Ciências Sociais, particularmente da Antropologia no Brasil, Mariza Corrêa tinha em Virginia Woolf uma de suas autoras preferidas. O gosto literário de Mariza Corrêa se faz ver em suas escolhas acadêmicas. Na obra "Antropólogas \& Antropologia" (2003), Corrêa provoca a leitura de uma "outra" história das ciências antropológicas. Uma leitura feita desde as "margens" das publicações acadêmicas cientificas, relatos de viagens e da produção de acervos museológicos. O título do livro de Mariza Corrêa faz menção ao título do livro de Adam Kuper "Antropologia e Antropólogos” (1973), destacando, assim, o caráter masculinista da história das ciências, dentre elas a Antropologia, tal qual elas vêm sendo descritas e arquivadas pelos grandes acervos dos "museus britânicos". A obra de Virginia Woolf aparece como uma inspiração tácita e permanente na instigante produção da história das ciências produzida por Mariza Corrêa. No dia em que escrevo esta nota, 3 de setembro de 2018, deve-se destacar, ainda, que uma das personagens da história da Antropologia brasileira trazida por Mariza Corrêa em "Antropólogas \& Antropologia" é a Dona Heloísa Alberto Torres (1895-1977), que compôs o corpo administrativo do Museu Nacional do Rio de Janeiro, sendo a diretora da instituição entre os anos de 1938 e 1955. Como nos conta Mariza Corrêa, Dona Heloisa era uma defensora do trabalho etnográfico, tendo exercido importante influência no modo como a antropologia brasileira passou a ser desenvolvida metodológica, teórica e politicamente. Dona Heloísa, ademais, era uma defensora das ciências, bem como dos acervos mantidos no Museu Nacional no Rio de Janeiro. Museu que no dia 2 de setembro de 2018 foi destruído pelo fogo que incendiou a instituição. 
Museu Britânico, todos produzidos por homens, retratavam a figura da mulher como inferior mental, física e moralmente. Quando não inferior, o retrato decorria de uma noção de extremos, fossem por atributos morais ou muito mais elevados, ou de extrema degenerescência: a normalidade seguia sendo masculina.

Em uma escrita que inspira cumplicidade, Virgina Woolf nos permite devaneios propositivos por meio dos quais são os homens escritores da imagética mulher ficcional que passam a ser por ela desenhados. Descritos por aquela que lê os textos. A leitora, assim, se torna autora de uma imagética ficcional dos homens, desenhados pelos atributos dos absurdos, tal qual a imagem de "um cachorro dançando". A escrita de Virginia Woolf, portanto, torce as localizações de autoria e objeto sobre o qual se escreve para, assim, fazer objeto os livros expostos na biblioteca do Museu Britânico. Ela se torna sujeito: a leitora mulher que sequer poderia acessar ao espaço da biblioteca sem ser levada e acompanhada por um homem.

O pano de fundo do cenário letrado das bibliotecas, museus e universidades britânicas pelo qual nos convida a caminhar Virgínia Woolf é caro para a disputa travada pelas escritas críticas negras e do "terceiro mundo" sobre autoria e objeto de conhecimento. Disputa sobre a qual a escrita de Frantz Fanon (1983 e 2005) tão fortemente se engendra. Muito antes das recentes análises produzidas no âmbito de universidades norte-americanas e europeias sobre como a "razão humanitária", vinculada ao ferramental da "saúde psiquiátrica" e epidemiológica, tem sido utilizada no "fortalecimento dos aparatos de Estado" e "controle das fronteiras" (Fassin, 2011); Frantz Fanon já escrevia sobre os aspectos coloniais que estruturam os cânones dos saberes psiquiátricos e da saúde.

Para o autor martinicano, que estudou psiquiatria na França e que atuou como psiquiatra na Argélia durante a guerra pela libertação nacional do país, os modos de operação e as práticas das ciências psi edificadas na academia francesa, bem como todo aparato de saúde epistemologicamente ocidental, era produtor e disparador das noções e sentimentos de "medo do outro" (Fanon, 1983). Frantz Fanon argumentava que os saberes ocidentais médicos-psiquiátricos produziam o "outro", mais especificamente os negros, como excessivamente corpos". E que por

5 Retiro essa expressão do livro de Virginia Woolf, "Um teto todo seu”. Nas páginas da obra, Woolf coleciona expressões utilizadas por autores, filósofos, dramaturgos e críticos homens sobre a atuação das mulheres em vários campos das artes, das literaturas e das ciências. A frase que relacionava a capacidade de mulheres serem compositoras de música e atrizes à imagem absurda de "um cachorro dançando", segundo Virginia Woolf, foi dita por uma personagem citada em seu livro, nomeada como Nikc Greene (Woolf, 2014: 80). 
serem só reconhecíveis como corpos por esses aparatos de saber, tinham sua humanidade vilipendiada, sendo impossível, portanto, serem os negros reconhecidos como sujeitos de práticas terapêuticas das ciências $p s i$ coloniais. O psiquiatra, autor e militante pela libertação argelina, nesse sentido, denunciava, por meio de sua escrita, a branquitude que configurava a noção de sujeito de "traumas", dores e saberes psíquicos. Denúncia que fazia ver a suposição de ausência psíquica e de dor que recaía aos não localizadas sócio e historicamente como "humanos": aos "outros" da humanidade. ${ }^{6}$

Virginia Woolf, Simone de Beauvoir e Frantz Fanon, foram alguns dos escritores que possibilitaram, por meio de suas obras, críticas à noção de uma suposta humanidade universal embasada em categorizações de masculinidade e branquitude ocidentais. As proposições de Beauvoir e de Woolf, bem como de Fanon, todavia, marcam escritos tecidos desde "experiências produzidas" (Scott, 1998), por atributos de feminilidades brancas e masculinidade negra. De fato, se o "outro" para o qual se volta a escrita de Fanon é "negro", as "outras” das filosofias e literaturas ficcionais para as quais se voltam Virginia Woolf e Simone de Beauvoir, são "mulheres”. O "outro negro" da psicanálise e do humanismo de Fanon é masculino. O "segundo sexo", as mulheres das quais falam Beauvoir e Woolf são inescapavelmente brancas e europeias.

Essa literatura crítica, sem dúvida, subverte as perguntas sobre "tornar-se nós". Fanon, Beauvoir e Woolf se voltam para quem são os "nós outros” de um “outro nós” bastante específico, mas reiteradamente tomado como universal: branco e masculino. Em seus argumentos, todavia, muitos outros emaranhados de diferenciação foram eclipsados por camadas de assimetrias de poder das quais os próprios autores eram parte. Nesse registro, faz-se significativo lembrar, aqui, de uma outra autora feminista. Autora que tem sua produção e trajetória datada ainda no século XIX.

Enquanto Simone de Beauvoir e Virginia Woolf denunciavam como as produções de saber engendradas desde epistemologias brancas e masculinas ocidentais imprimiam uma imagética

6 Sobre a trajetória política, intelectual e biográfica de Frantz Fanon, recomendo fortemente a leitura do livro de Deivison Mendes Faustino, "Frantz Fanon: um revolucionário particularmente negro" (2018). As intuições sobre a relação da crítica epistemológica e política de Fanon com aquelas produzidas por Simone de Beauvoir decorre da leitura do livro de Faustino. Cabe mencionar que Fanon foi amigo pessoal de Sartre e de Beauvoir. Não por acaso, contudo, o filósofo existencialista branco e francês parece ter deixado claro, no prefácio que escreveu para o livro de Fanon "Os condenados da terra", publicado pela primeira vez no ano da morte de Fanon, 1961, que não compreendia a amplitude e força das análises do amigo vindo das colônias francesas Martinica e Argélia. Infelizmente, por muito tempo a escrita de Fanon ficou conhecida sob a sombra do decepcionante prefácio de Sartre (Faustino, 2018). A leitura da obra de Frantz Fanon pode revelar, entretanto, que os caminhos analíticos e de ativismo tomados pelo psicanalista martinicano estavam muito mais próximos das provocações literárias produzidas por Simone de Beauvoir. 
feminina embebida de atributos de "fraqueza" física, mental e moral, bem como de adjetivações de “docilidade", o discurso de Sojorner Truth (2012[1851]), proferido em 21 de junho de 1851, tinha sua centralidade na pergunta: "Não sou eu uma mulher?". A mulher negra, que havia sido escravizada durante quarenta anos, ao longo dos quais trabalhara e lutara arduamente pela conquista de sua liberdade, propunha o olhar de estranhamento à categoria mulher que vigorava no púlpito da demanda sufragista do movimento de mulheres do século XIX, nos Estados Unidos. Se as justificativas acionadas pelos argumentos afeitos ao impedimento do direito das mulheres votarem e serem votadas faziam referência às suposições de fraqueza e polidez que eram vinculadas a uma certa feminilidade - a branca -, Sojorner Truth questionava o público daquela conferência que teve lugar em Ohio: "Não sou eu uma mulher?".

As palavras de Sorjoner Truth referiam-se ao fato de as mulheres negras escravizadas nunca terem sido relacionados os atributos de delicadeza e fraqueza que categorizavam as mulheres brancas naquelas arenas políticas. Ao contrário, Sorjoner Truth expunha que havia trabalhado tanto quanto um homem (muito mais do que os homens brancos para os quais ela dirigia suas palavras), que havia apanhado tanto quanto um homem escravizado, que poderia comer tanto quanto qualquer homem, desde que tivesse acesso à comida. Ela ainda dizia que nunca havia recebido os "cuidados" que eram reservados para as mulheres brancas, como apoio para subir a uma carruagem ou ajuda para atravessar uma poça e, principalmente, que a maternidade de seus filhos nunca havia sido respeitada ou reconhecida. ${ }^{7}$ Por meio dessas colocações que estranhavam as categorizações que produziam a "mulher" da demanda pelo sufrágio, Sorjoner Truth possibilitou inferir as muitas tramas que intersectam as produções de assimetrias entre "nós" e "outros".

A partir da fala de Sorjoner Truth, autoras como Patricia Hill Collins (2012) e Angela Davis (2016) produziram, posteriormente, contundentes críticas aos feminismos brancos euroamericanos. Patricia Hill Collins, particularmente, argumentou que enquanto as mulheres brancas demandavam igualdade de direitos político-civis, as mulheres negras, ao não serem relacionadas a

7 "Aquele homem ali diz que é preciso ajudar as mulheres a subir numa carruagem, é preciso carregar elas quando atravessam um lamaçal e elas devem ocupar sempre os melhores lugares. Nunca ninguém me ajuda a subir numa carruagem, a passar por cima da lama ou me cede o melhor lugar! E não sou uma mulher? Olhem para mim! Olhem para meu braço! Eu capinei, eu plantei, juntei palha nos celeiros e homem nenhum conseguiu me superar! E não sou uma mulher? Eu consegui trabalhar e comer tanto quanto um homem - quando tinha o que comer - e também aguentei as chicotadas! E não sou uma mulher? Pari cinco filhos e a maioria deles foi vendida como escravos. Quando manifestei minha dor de mãe, ninguém, a não ser Jesus, me ouviu! E não sou uma mulher?”. Trecho da fala de Sorjoner Truth publicada no site do Geledés - Instituto Mulher Negra. https://www.geledes.org.br/sojourner-truth/ (acesso em 17 de Setembro de 2018). 
atributos de gênero localizados nos enquadramentos da feminilidade branca, lutavam pelo reconhecimento da própria humanidade. $\mathrm{Na}$ base das análises de Collins está o entendimento de ser "gênero", intersectado com "raça", categorias produtoras dos e produzidas pelos marcos assimétricos que humanizam e/ou desumanizam pessoas e populações.

Se a fala de Sorjoner Truth - para quem a luta pelo sufrágio e a demanda pelos direitos políticos era legitima - evidencia as diferenças brutais que a própria categoria mulher imprimia nas relações, ao não considerar as desigualdades raciais, o posicionamento crítico de Emma Goldman (1911) quanto ao movimento sufragista se volta para as hierarquias de classe. A autora, que nasceu na Lituânia, em 1869, de onde fugiu aos dezesseis anos em decorrência dos abusos a que seu pai a submetia, viajou junto de sua irmã mais velha, para os Estados Unidos, país onde passou a trabalhar na indústria têxtil e a atuar fortemente no movimento operário e sindicalista (Goldman, 2006 [1931]). Desde uma perspectiva marxista e anarquista (muito similar à que Angela Davis (2016 [1981]) desenvolveu anos depois), Goldman se posiciona contra o movimento sufragista e a luta pelos direitos políticos. Para ela, a demanda pelo acesso ao voto era uma demanda pela legitimidade da submissão das classes pobres e operárias ao que ela chamou de "fetiche" da lei. Para Goldman, as próprias práticas de Estado, das quais o voto e as condições de trabalho nas fábricas eram intrinsecamente parte, serviam como processos de desumanização das mulheres negras, migrantes e trabalhadoras, incluindo as trabalhadoras sexuais em suas análises. Mulheres que não se enquadravam nas categorizações normativas que a lei impunha.

Tendo em vista todo o cabedal crítico impulsionado pelas palavras de Emma Goldman e de Sorjoner Truth, iniciar um ensaio propositivo sobre categorias de diferenciação como "gênero", "raça" e "classe" para a produção das ciências sociais com autoras como Woolf e Beauvoir pode parecer estranho. A escolha, todavia, decorre do entendimento de ser a epistemologia feminista, em sua relação com as indagações críticas aos processos coloniais, fundamentalmente voltada para a produção analítica sobre quais sujeitos foram marcados nos cânones das bibliotecas, dos museus e das práticas políticas como os "nós" autores e quem foram os categorizados como sujeitos “outros”, sobre os quais recaíam as escritas. Cabe, entretanto, subscrever que na elaboração de suas apreciações sobre o sujeito "outro", autoras como Woolf e Beauvoir produziram uma "categoria mulher" (Piscitelli, 2008) a qual universalizava atributos da feminilidade branca ocidental e incidia no desdobramento de sujeitos "outros" a essa "categoria mulher". 
Desde as proposições dos argumentos da autora feminista marxista Gayatri Spivak (2010), deve-se destacar que os processos que compreendem a racialização de sujeitos "específicos" decorrem de disputas e hierarquias de poder que tornam "transparentes" a raça de "outros". Estes tomados como genéricos. Deste modo, a "categoria mulher" sobre a qual repousa a produção filosófica e literária das autoras feministas brancas euro-americanas decorre do entendimento de não serem elas categorizadas por atributos de classe e raça tanto quanto as mulheres negras e do "terceiro mundo". A "transparência" do autor masculino implicada nas escrituras e acervos das bibliotecas e museus britânicos e franceses, sobre a qual emularam as escritas de Beauvoir e Woolf, fora, de outro modo, reiterada em suas produções. A categoria mulher, assim, passou a ser uma categoria produzida desde a suposição da "transparência" do sujeito autor feminino branco colonial.

Desde esse cabedal crítico à categoria gênero como um "eixo de diferenciação" (Crenshaw, 2002) primordial para a compreensão das relações de poder, autoras como Spivak e Donna Haraway (2004) incitaram proposições analíticas acerca de como "localizações sociais" (Mahler e Pessar, 2001) dos autores das "ciências" implicam em produções de conhecimento diversas e recorrentemente subjugadas. No exercício de tentar sistematizar o verbete "gênero" para um dicionário marxista, Haraway argumenta que a vivência das relações e assimetrias de gênero dependem do campo semântico, do idioma, das noções de ancestralidade e das relações de trabalho e consumo que atravessam experiências e possibilidades de trajetórias particulares. A exposição da dificuldade em sistematizar o conceito de gênero como uma noção comum, com a qual Haraway inicia a produção de seu verbete, contudo, não resulta no estilhaço de campos semânticos epistemológicos absolutamente paralelos e dissociados. Antes, implica no reconhecimento de que toda produção de saber decorre dos processos que situam e diferenciam aqueles que são sujeitos de seus enunciados. Não há, portanto, em nenhuma ocasião e desde nenhuma possibilidade de escrita e autoria científica e/ou ficciocional, transparência da autoria. Esta, em si, é produzida pelas interseccionalidades que localizam os autores em suas relações nas produções de saber.

Desde essas relações que conformam e diferenciam campos epistemológicos de acordo com categorizações que os localizam segundo atributos raciais, de gênero, classe e sexualidade, para citar apenas alguns exemplos, a crítica de Gayatri Spivak (2010) vai além das proposições de Donna Haraway. Como autora dos estudos culturais, indiana que migra para os Estados Unidos e acende às cadeiras das principais universidades estado-unidenses, os argumentos de Spivak escrutinam as 
formas "difusas e capilares" por meio das quais Foucault (1979) desenhou as disputas dos "lugares de enunciação". A autora que integra o cânone dos chamados "estudos subalternos" (Mignolo, 1994) argumenta que há uma hegemonia colonial, marcadamente ocidental e branca, na produção epistemológica a qual, mesmo que embebida em atributos de "pós-colonialidade", incorre em práticas de subjugação de determinados conhecimentos em detrimento de outros.

Os argumentos de Spivak podem ser acionados no que se refere as análises críticas acerca de, por exemplo, quais literaturas e referências bibliográficas são consideradas "clássicas", "centrais", "obrigatórias" para a formação dos alunos nas ciências sociais, e quais são reiteradamente relegadas ao âmbito dos "conhecimentos específicos", pingentes. Nesse registro, as críticas de Spivak aos processos de produção da epistemologia canônica das ciências humanas se aproxima do entendimento crítico de Joan Scott, de que a literatura historiográfica se configura discursivamente como epistemologicamente "transparente", enquadrando, ao longo de décadas, a "história das mulheres" (Perrot, 1995) e a "história dos trabalhadores" (Friedmann, 1963), por exemplo, nas estantes das histórias miúdas ou da "vida privada".

Ademais, em consonância com autores como Edward Said (2007) e Chandra Mohanty (1984), Spivak disserta que a produção de saber colonial, ao subjugar formas de conhecimento e campos semânticos de saber das populações colonizadas, termina por produzir figuras imagéticas sobre as "mulheres na Índia" (Spivak, 2010), "mulheres muçulmanas" (Abu-Lughod, 2002), "mulheres do terceiro mundo" (Mohanty, 1984), bem como "homens negros" (hooks, 2004), tão ficcionais e absurdas quanto as imagens sobre "a mulher" que Virginia Woolf encontrava na biblioteca do Museu Britânico.

A importância, ou a imprescindibilidade, das categorias de diferenciação para as ciências sociais e humanas está, portanto, na necessidade meta analítica e metacrítica voltada para a produção de saberes. Está na atenção constante sobre quem somos nós e que autores somos quando enredamos relações com o campo epistemológico e, principalmente, com nossos campos etnográficos. Reconhecer que a nossa produção é inescapavelmente tramada por categorias de diferenciação intersectadas é analisar para além dos dispositivos normativos da "igualdade" e da “diferença” (Padovani, 2016b). É antes fazer ver como assimetrias são negociadas e disputadas pelos saberes e epistemologias que esquadrinham reiteradamente "nós" e "outros" em corpos racializados, sexualizados e generificados através de relações de poder e intimidade. 


\section{DAS FRONTEIRAS DAS INTERSECCIONALIDADES}

Tal como o "estranhamento" à categoria mulher que Sorjoner Truth expõe em seu discurso proferido em 1851 pode aventar, a noção de interseccionalidade foi produzida no bojo dos feminismos negros, "pós-coloniais" e do "terceiro mundo". Produzida, portanto, por autoras feministas que, desde suas "localizações sociais" (Mahler e Pessar, 2001), não reconheciam na "mulher" branca e ocidental o sujeito político "nós" da "irmandade feminista" (Truth, 2012; Alexander e Mohanty, 2010). Por meio de análises que faziam ver que não existem relações sociais que não sejam atravessadas por "marcadores sociais das diferenças" (Moutinho, 2014) ${ }^{8}$ ou “categorias de diferenciação" (Piscitelli, 2008) ", as proposições interseccionais embaralharam, ainda, supostas separações entre "arenas públicas" e "campos políticos da intimidade".

A tese de Anne McClintock (2010) pode ser tomada como um exercício analítico exemplar desse embaralhamento. Seu livro começa com a imagem de um "mapa", retirado do best-seller $A s$ Minas do Rei Salomão, de Henry Rider Haggard. No romance, algum lugar do sul da África, que não é exatamente localizável, é representado como as “terras virgens” a serem penetradas pelos ingleses brancos. Na história, o mapa das terras sul-africanas que serve de guia para os exploradores britânicos fora desenhado por um mercador português que usara o seu próprio sangue para

8 Laura Moutinho (2014), em um artigo de fôlego, elabora uma ampla e densa discussão sobre como marcadores sociais da diferença vêm sendo articulados nas reflexões acadêmicas e políticas no Brasil. A análise da autora parte do trabalho fino de coleta investigativa em plataformas como Scielo e Jstor, com vistas a elaboração de um quadro que permite visibilizar como "gênero", "raça", "sexualidade" e "classe" vêm sendo articulados nas produções acadêmicas, particularmente no tocante a reflexões que fazem referência a produção de nação e políticas de Estado. Não há, aqui, como resumir ou mesmo fazer as merecidas deferências ao trabalho feito por Laura Moutinho o qual, inclusive, impulsiona o início da escrita deste meu breve ensaio. Vale destacar que, em seu artigo, Moutinho tem um cuidado analítico absolutamente sofisticado, particularmente, com relação à literatura feminista e o campo dos estudos sobre sexualidade que vinham sendo publicados desde a década de 1980. Cabe a mim tão somente recomendar fortemente essa leitura que, junto com artigo de Adriana Piscitelli (2008), configura uma espécie de mapa das interseccionalidades nas ciências sociais brasileiras.

9 Propondo analisar como categorias de diferenciação eram articuladas nas relações vivenciadas por suas interlocutoras, mulheres brasileiras migrantes em países europeus como Espanha, Portugal e Itália, Adriana Piscitelli produziu, em 2008, uma análise precisa sobre o cenário e as disputas que configuraram a produção e a inserção da noção de interseccionalidades nos estudos de gênero. A autora elaborou, inclusive, uma didática classificação por meio da qual os entendimentos de interseccionalidades cunhados desde as arenas normativas legais norte-americanas, particularmente pela jurista Kimberlé Crenshaw (1989 e 2002), eram distinguidos da reflexividade interseccional produzida desde trajetórias diaspóricas, tal como ocorre com Avtar Brah (1996). Reforço a recomendação das leituras dos artigos de Moutinho (2014) e Piscitelli (2008). 
registrar, num pedaço de roupa rasgada, os "seios da montanha" e a boca da caverna do tesouro onde duas entradas proibidas [buracos e fossas] os levariam a uma mina de diamantes. Para obterem "sucesso" na aventura, contudo, os exploradores deveriam enfrentar e matar a velha mãe, ou "o gênio do mal da terra". Este, representado como "bruxas velhas e negras" a serem por eles penetradas e por eles rasgadas. Desde os buracos, ou das fossas anais das bruxas negras, os exploradores europeus deveriam sair carregando diamantes: as riquezas escondidas nas terras antes inexploradas.

As imagens acionadas pela autora no início de seu livro evidenciam que o "projeto do imperialismo" se faz desde o entremeado "culto à domesticidade". Evidenciam, portanto, que historiografias coloniais, embebidas de sangue e espermas, violências, penetrações e afetos são materializadas nas relações dos sujeitos que corporificam, em suas relações, as intersecções de raça, gênero e classe. Intersecções entre categorias que, para a autora, não são distintos reinos da experiência, mas que existem em relação entre si (McClintock, 2010: 19). Deste modo, ao contrário do que propôs Scott (1995), não há na formulação interseccional de McClintock um "eixo de diferenciação" primeiro. Não há sujeitos que não estejam em relação íntima e política simultaneamente. Relações essas imprescindivelmente produzidas pelos "embates coloniais" das assimetrias de poder atravessadas por raça, classe, gênero e sexualidade.

Como já destacou Adriana Piscitelli (2008), o modo como Anne McClintock formulou “interseccionalidades” é distinta da forma como Kimberlé Crenshaw (2002) cunhou essa noção. Para a jurista norte-americana, professora nas faculdades de direito em Universidades como Columbia e Califórnia, raça e gênero são diferentes eixos de diferenciação que podem ou não se entrecruzar. Crenshaw, voltando-se principalmente para o campo da segregação na produção de políticas públicas e de proteção estatal, faz uso da metáfora das avenidas. Segundo ela, raça pode ser compreendida como uma "avenida" e "gênero" como outra. Nesse desenho, uma mulher branca estaria posicionada na avenida do gênero, um homem negro, por sua vez, na avenida da raça. No tocante a mulher negra, o cruzamento das avenidas se faz. A mulher negra encontra-se no cruzamento da avenida da raça com a do gênero. Como a autora argumenta, os carros de resgate, ou seja, as políticas públicas estatais de proteção social, não param nos cruzamentos, somente os atravessam.

O entendimento das interseccionalidades por meio de "eixos" de diferenciação independentes, tal como desenhado por Crenshaw, possibilita localizar apenas determinados 
sujeitos nas vias de diferenciação racial, outros nas de gênero e outros, ainda, na de sexualidade. Somente alguns sujeitos seriam marcados pelos entrecruzamentos dos eixos. Desde essa produção normativa das interseccionalidades, o homem branco heterossexual, por exemplo, não ocuparia qualquer avenida. Não estaria marcado por nenhum atributo que, na formulação de Crenshaw, mais do que produtor de diferenciação, seria produtor de desigualdades.

Em sua análise crítica aos usos e à formulação do conceito de interseccionalidade, Carla Akotirene (2018) sublinha que a formulação de Kimberlé Crenshaw implica uma quebra da visão inocente do papel político do Estado. Akotirene expõe que o modo como Crenshaw cunhou a noção de interseccionalidade possibilitou capturar o racismo institucional estruturante dos aparatos Estado, bem como do próprio capitalismo. Desse modo, podemos dizer que o "homem branco heterossexual" não aparece nas avenidas que configuram os "eixos" de racialização e desigualdades de gênero e sexuais porque esse seria o sujeito da autoria dos mapas das opressões. O desenho por onde passam, param ou atravessam as políticas públicas de acesso a direitos, portanto, seria, assim, marcado pela branquitude masculina.

Por diferentes abordagens teóricas, perspectivas e planos de interlocução (antropologia e estudos culturais; políticas públicas e aparato jurídico de Estado) as escritas das interseccionalidades de McClintock e Crenshaw revelam um ponto de conexão. Seja na forma de contornos nacionais ou de cruzamentos de avenidas, são imagens corporificadas de atributos de feminilidades e racialização que materializam as fronteiras. Não por acaso, fronteiras, bem como seus atravessamentos, são imagens e processos caros para a formulação feminista sobre interseccionalidades.

Tendo em vista que a noção de interseccionalidade fora cunhada nas "margens" (Das e Poole, 2004) dos feminismos, a mesma refere-se às tensões e aos contatos fronteiriços das categorizações de gênero, classe, raça e sexualidade que fundamentam saberes e embates das diásporas coloniais. Virginia Woolf e Simone de Beauvoir sem dúvida escreviam acerca de um sujeito outro da humanidade masculina, mas elas o faziam sem atravessarem as violentas fronteiras que compuseram a trajetória de Sorjoner Truth. Na base da formulação de interseccionalidades estão os processos coloniais e imperiais que escravizaram e desumanizaram politica e discursivamente mulheres negras, indígenas, latinas, asiáticas. As mulheres das colônias do império e do "progresso" euro-americano (McClintock, 2010; Quijano, 2005). As narrativas diaspóricas e das/nas fronteiras, assim, são fundantes para o desenvolvimento do entendimento de processos 
de diferenciação e desigualdade nas tramas das interseccionalidades. Tramas diaspóricas transnacionais que permitem galgar a "descolonização" dos feminismos.

Pela proposição de "descolonização" dos feminismos, Chandra Mohanty (1984) defende o deslocamento das produções feministas frente a centralidade atribuída aos feminismos ocidentais. Ao propor analisar e implodir a categoria monolítica das "mulheres do terceiro mundo", a autora indiana evidencia como as experiências vividas nos mais diversos lugares e contextos são diferentemente marcadas por assimetrias de classe, raça e gênero de modo a só poderem ser levadas em conta desde perspectivas de atravessamento das fronteiras. Mohanty, assim, coloca as diversas fronteiras em escalas relacionais, ilustrando que estas tem servido para os propósitos colonialistas dos feminismos brancos por estar nelas sendo assimilada a noção da "diferença do terceiro mundo". ${ }^{10}$ Tal noção de diferença entre "mulheres do primeiro e do terceiro mundo", argumenta a autora, é o que permite que sejam escritos, por exemplo, livros sobre "as mulheres da África", ou "as mulheres da China", em contraposição a impossibilidade de serem publicados compêndios sobre "as mulheres da Europa".

A percepção das diferenças racializadas entre "mulheres do primeiro mundo e do terceiro mundo" passa a ser sentida em sua carne quando, em decorrência de seu deslocamento migratório da Índia para os Estados Unidos, Mohanty é localizada, no país de destino, como "uma mulher de cor”. Categorização antes nunca relacionada a ela na Índia. Através das descrições de sua própria vivência nos movimentos feministas, contudo, a autora argumenta que, por meio do processo de seu deslocamento transnacional, compreende que as fronteiras compuseram suas experiências mesmo antes de ela imaginar que migraria da Índia para os Estados Unidos. As fronteiras, assim, passam a ser entendidas por Mohanty como âmbitos inclusivos e excludentes de sujeitos racializados e categorizados diferentemente nas relações segundo classe, gênero e sexo.

As análises de Chandra Mohanty podem ser vinculadas ao modo como Avtar Brah (1996) define "diáspora". Para a autora, as diásporas são vistas em termos genealógicos, no sentido de produzirem o efeito de historicidade de diferentes trajetórias e mobilidades, as quais são analisadas de modo a colocarem em relação contextos políticos, afecções sociais, subjetividades e identidades nacionais. Os sentidos que ambas autoras, Brah e Mohanty, atribuem às mobilidades transnacionais

10 Vale dizer que Deivison Faustino Mendes (2018) chama atenção para como Fantz Fanon analisava, de modo muito similar ao de Chandra Mohanty, as noções de terceiro mundo e fronteiras. Frantz Fanon, certamente, apresentase como uma inspiração e fundamentação das proposições descoloniais dos feminismos. 
são densamente embebidos pela noção de interseccionalidade. Para todas as autoras aqui citadas, as interseccionalidades são pensadas como os processos mediante os quais os indivíduos se tornam sujeitos. Mas faz-se importante denotar que suas análises interseccionais e sobre fronteiras decorrem do modo como elas atravessaram e subjetivaram suas experiências. A conceituação de diáspora proposta por Avtar Brah, assim, decorre de seus próprios processos diaspóricos. A autora nasceu na Índia e cresceu em Uganda, país de onde fugiu com a família antes do processo de expulsão dos asiáticos do país, na década de 1970. Em fuga, foi recebida sozinha, sem a família, para estudar nos Estados Unidos e, depois, na Inglaterra. O modo como Brah define diáspora, portanto, vincula-se ao como seus fluxos transnacionais dão sentido e historicidade para sua trajetória. Ou seja, mais do que repousada em uma identidade nacional, o processo de subjetividade em Avtar Brah se dá pelo deslocamento, pelos atravessamentos diaspóricos das fronteiras.

Se Mohanty e Brah partem de suas trajetórias diaspóricas transnacionais para inferir análises interseccionais das diferenças e desigualdades, Lélia Gonzalez (1988a) perfez sua escrita analítica desde fronteiras ainda "outras". Sem se situar ou fazer deferência ao cabedal semântico das “interseccionalidades", forjado desde a produção redigida em idioma inglês e posterior a sua escrita subversiva, a antropóloga negra brasileira propôs embaralhamentos que objetivavam a implosão do léxico gramatical da branquitude acadêmica.

Por meio da categoria de "amefricanidade", Lélia Gonzalez desafiou as proposições dos feminismos negros norte-americanos. Feminismos os quais, para a autora, eram insuficientes frente ao entendimento das malhas complexas que enlaçavam relações de poder raciais e geopolíticas do terceiro mundo. Nesse registro, a noção de amefricanidade, cunhada por Lélia Gonzalez, é implicada na trama que enreda violência, poder e resistência na experiência da colonialidade latina. Uma experiência de embate colonial que é embebida tanto na diáspora negra quanto no genocídio dos povos indígenas das Américas. A interseccionalidade expressa na amefricanidade de que fala Gonzalez, é o exercício político semântico de colocar no centro da produção epistomológica feminista e das ciências sociais brasileiras, a história de luta e resistência dos colonizados frente aos colonizadores. Uma “outra" torção de autoria. Uma escrita da história em linguagem “outra”: o pretoguês.

Como demonstra Claudia Pons Cardoso (2014), pretoguês de Lélia Gonzalez é o idioma do encontro. É a “marca de africanização do português falado no Brasil” (Gonzalez, 1988: 70). Idioma no qual repousa a análise crítica feminista antropológica de Lélia Gonzalez. Um idioma que 
em si, pelo seu uso textual na produção de saber, já descoloniza os cânones acadêmicos. Mas Lélia Gonzalez não chamaria assim, ela não falaria só em descolonização. Antes, diria que o pretoguês, a expressão ladina ${ }^{11}$ da linguagem, é ferramenta que desbunda. O verbo desbundar, que significa causar impacto e encantamento, é também verbo que contém a parte do corpo bunda.

Bunda, que tão violentamente foi acionada pelos projetos e penetrações coloniais para categorização das mulheres negras como "excessivamente corpos", é rearticulada na escrita de Lélia Gonzalez como elemento revolucionário e de resistência. Usando a narrativa mítica da líder da revolução jamaicana, Nanny, a qual teria protegido seu exército das balas vindas das armas imperiais britânicas com a força de suas nádegas (Cardoso, 2014 e Gonzalez, 1988b), Lélia Gonzalez imprime imagens e historiografias que subvertem as narrativas de embate colonial, tal qual a trazida por Anne McClintock. A bunda, em Gonzalez, é arma de subversão do poder colonial, e é também o enfrentamento do léxico epistemológico acadêmico por meio da parte que seria excessivamente corpo. O desbunde da escrita de Gonzalez, assim, é interseccional e fronteiriço. Uma ferramenta prática de colonização às avessas do academicismo branco pelo idioma preto. Mais do que isso, é o embaralhamento inescapável, na forma da linguagem que produz o conteúdo, entre a domesticidade do corpo e as arenas públicas da guerra e da produção de saber.

Se Lélia Gonzalez formula análises interseccionais por meio de uma linguagem epistemológica que leva em conta o que é excessivamente corpo, é na figura da "mulata" que a escrita política-pessoal de Angela e Onik'a Gilliam (1995) encontra as fronteiras das interseccionalidades.

Em texto escrito ao longo dos muitos anos em que Angela Gilliam, antropóloga norteamericana negra, fez seu trabalho de campo e de formação acadêmica no Brasil, sempre em companhia de sua filha Onik'a, as autoras analisam como assimetrias de poder são negociadas nos atravessamentos das fronteiras transnacionais entre o Brasil da ditadura militar e os Estados Unidos “democrata capitalista branco”. Entre as décadas de 1960 e 1970, por exemplo, era apenas Angela, uma "mulata tamanho família" (Gilliam, 1995: 537) que, por ser norte-americana e antropóloga, poderia dizer no jornal O Pasquim, que as estruturas de poder e de diferença de classe e gênero, no Brasil, são racistas. O texto, escrito por mãe e filha, é um exercício interseccional de linguagem que

11 Astuta, malandra, "mestiça”. Expressão que Lélia Gonzalez faz uso em sua escrita para referir-se, inclusive, a América Latina. Uma expressão pejorativa em idioma espanhol a qual Gonzalez subverte, produzindo-a como noção que expressa expertise de resistência. 
coloca no centro da escrita afetos e pessoalidade fazendo desbundar que intimidade e política, longe de serem reinos distintos da experiência, são constituidores da produção do saber.

Inspirada pelas provocações semânticas e interseccionais de Lélia Gonzalez, Anne McClintock, Angela e Onik'a Gilliam, não poderia terminar este ensaio com uma escrita que pretendesse ser transparente. Se toda produção de saber é política e pessoal, a feitura analítica das Ciências Sociais é tributária das trajetórias que atravessam fronteiras e que, por meio delas, negociam, fazem e refazem assimetrias de poder. Assimetrias nunca transparentes porque toda autoria é localizada. Assim que não há como fazer ciências sociais sem uma análise crítica das categorias de diferenciação. Porque não há como fazer relações e saberes que não estejam nas fronteiras do que é excessivamente corpo pelas suas epistemologias.

\section{DOS EMBATES DAS AJUDAS ${ }^{12}$}

Lembro de estar sentada diante do espelho com os cabelos lambuzados de uma química fedorenta que minha mãe passava fio a fio para alisar os cachos. Cabelos cacheados não podiam ser bons sinalizadores naquela minha escola de brancos ricos do $\mathrm{ABC}$ paulista. Tanto não eram que eram razão de atenção. Encaracolados mereciam cautela naquela terra de lisos. E eu, aos doze anos, alinhava as curvas sinuosas dos enrolados indisciplinados. Lembro de fazê-lo com a ajuda de minha mãe, disciplinadora, lisa, chorosa; enrolada nos nós daqueles cabelos amaldiçoados por uma raça estranha. Afinal que raridade poluidora seria a destes caracóis enroladores?

Foi no avião, pouco menos de vinte anos depois, com a cabeleira solta em dias de viagens por uns Estados Unidos pedagogicamente repartidos em branco, negro e latino, que me vi, novamente, diante daquele espelho. Na pequena tela, nas costas do assento da frente, eu, latina branca encaracolada, assisti The Help, chamado em português de Histórias Cruzadas. O filme, baseado no livro de Kathryn Stockett, conta as relações estabelecidas pelas meninas brancas, de

12 Uma versão deste texto foi publicada, em 2013, no site do Núcleo de Pesquisa em Diferenças, Gênero e Sexualidade da UFSCar, Quereres. A primeira versão, chamada “As negras de Avtar Brah" (título sugerido por Carolina Branco), foi retirada do ar junto com a plataforma da revista online que passou a ser lotada no Núcleo de Pesquisa em Diferenças, Direitos Humanos e Saúde da Faculdade de Saúde Pública da UNIFESP http://www.quereres.sites.unifesp.br/categoria/ponto-q/page/4/ (acessado em 17 de Setembro de 2018). 
vinte e poucos anos, recém-casadas, recém-mães, e, uma recém-graduada, com as mulheres negras, de quarenta e poucos anos, recém-trabalhadoras domésticas, recém-livres, em Jackson, cidade do estado de Mississipi, durante a década de 1960. Voltando de uma estranha temporada pelos suls daquele país, as imagens do filme selavam minhas impressões.

Todos os anos, o Women's Studies da Duke University em Durham, North Caroline, US A, faz um workshop sobre teoria feminista. São convidados importantes personagens de referência na área que sobem a um púlpito e narram acerca da produção de novos conceitos, novas expertises, novas metodologias, novas percepções: inovações para a teoria feminista mundial. Neste ano, se nem todos os expoentes eram brancos norte-americanos, todos eram professores de universidades brancas norte-americanas: lisas. No auditório cheio, disputado, estudantes bem vestidos, portadores de óculos e cabelos minuciosamente estilizados, acotovelavam-se, sentavam-se no chão para poderem ouvir, com atenção, os ensinamentos dos sábios teóricos tecedores de linhas conceituais a serem aplicadas pelo desenvolvimento da prática das ciências sociais, antropológicas: o progresso.

Estava eu, zonza dentre esses cotovelos. Brasileira, fui, junto com mais outras quatro garotas estudantes "promissoras do terceiro mundo" - leia-se uma congolesa, uma mexicana, uma croata, uma islandesa (nórdica, branca bem afastada, quase exótica) - beneficiada com uma bolsa que me levou de Santo André à Guarulhos, de Guarulhos à Nova York e, de lá, ao sobrevoo pelos rios que entrecruzam Tennessees e Mississipis à friagem fervilhante sulista daquele hemisfério norte.

Foi nas escalas de filas; atendente a atendente, policial a policial, em Nova York, que eu pensei que os Estados Unidos eram negros. Foi naquele aeroporto gelado, grosseiro, caro, com nome de herói democrata que passa gel nos cabelos lisos, que sentei a espera do voo à Durham, North Caroline; sul longínquo daquele norte central fronteiriço. Ao meu lado, um senhor simpático carregava um anel em cada dedo de pele preta; na cabeça, os cabelos brancos penteados e, no tronco, um blazer bege. Lia The New Yorker. Íamos ele e eu descer. Desci em Raleigh-Durham, e corri à fila dos taxistas. Clientes, brancos, sentavam-se atrás. Foi onde sentei.

Na direção estava Halli, somaliano morador de Raleigh-Durham pelos últimos doze anos. Dirigindo, contou-me da Somália, da comida, do sol, das estações, contou do medo que tinha de seus filhos - adolescentes, negros e africanos - serem presos nos Estados Unidos (onde prisões privadas enquadram latinos, africanos e seus filhos norte-americanos). Contou que por esse medo, 
ele e sua esposa resolveram que filhos e mulher iriam morar na Somália. Só, Halli permaneceria nos Estados Unidos trabalhando como taxista. No caminho, naquela estrada deserta que cruzam cidades sem calçadas, Halli disse que somente como taxista de um provinciano aeroporto norteamericano conseguia manter os filhos na Somália. Que só com os dólares de Halli é que seus filhos podiam comer comida orgânica escapando, assim, da prisão e dos pesticidas norte-americanos que, testados nas lavouras somalianas, afetam o sistema nervoso de quem os come. Halli não os come. Não os comem seus filhos. Mas pesticidas, prisões e dólares americanos dirigem suas vidas desde aquelas estradas vazias até os caminhos da mercearia somaliana.

Desci, mais uma vez. Agora num hotel. Eram recepcionistas e lençóis brancos. Arrumadeiras morenas, mexicanas. Perguntei pelo ônibus que me levaria à universidade, ao que me responderam que não havia; como não havia, também, caminhos pelas calçadas. Só havia carros. “É perigoso transitar por onde caminham carros, você pode ser atropelada e o trajeto é vazio". O taxista que me levou desde ali até a universidade desta cidade sem transporte público, era Gabriel, do Suriname. Velho garimpeiro, se sentia um tanto de Roraima que falava até português. Tinha casado com uma cozinheira que trabalhava meio período como puta no garimpo fronteiriço, mas perdera todo o ouro, de modo que foi se juntar a seu irmão naquelas terras de asfalto liso. Falava pouco inglês, não precisava. Cliente não trocava muita conversa e o bairro em que fez tua casa era latino nas margens dos rios negros daquela alva Carolina que conheci, enfim, ao entrar no campus da universidade do Duque. Casas neogóticas um dia mantidas e habitadas por grandes proprietários brancos das terras onde escravos negros plantavam tabaco. Senhores preocupados com a educação de seus filhos homens. Desci do carro de Gabriel. Vínhamos, ele e eu, de um sul diferente daquele. Vínhamos um sul não tão diferente daquele. Eu, paulista, branca, antropóloga, feminista descia do carro. Ele surinamesco, nortista, garimpeiro, de um latino mais escuro que o meu, seguia no carro; viria me buscar mais tarde.

Mas naquele auditório eu era um pouco Gabriel. Achatada por entre os cotovelos anglo falantes, meus latins encaracolados eram pretos. Numa escala diferente da de Halli, da dos policiais atendentes do aeroporto JFK, era eu a preta bárbara civilizada: tão branquinha que decepcionava as expectativas do projeto de progresso colonizador. Nada queriam ouvir de mim que vinha de longe. Como com Gabriel, a quem se ajuda não se troca conversa. Não havia troca possível comigo ali, naquele auditório. Só a escuta civilizadora que vinha iluminar a minha prática e teoria sulista do mundo; lá de baixo. 
Descia. Falavam de etnografias feitas com travestis filipinas, equatorianas; com trabalhadoras mexicanas, portenhas, croatas, congolesas; com índias neozelandesas. Falava-se de conceitos que nomeavam zonas fronteiriças das sexualidades, dos cuidados, dos afetos; Brown, chamavam-nas. As fronteiras eram marrons. E nós, convidadas, ajudadas, cuidadas: brasileira, congolesa, mexicana, croata, islandesa, sentíamos estranhas familiaridades com a tal novidade das ciências sociais. Éramos nós as tais zonas browns. Éramos nós as marrons suficientemente brancas para estarmos ali sentadas, servidas de café, água, comida, lençol e transporte dos mais marrons do que nós. Nós, marrons de tantas línguas, trocávamos olhares e, depois da pouca intimidade enrolada pelos embaraços, alguns certos risos sarcásticos dos que descem à área de serviço e sentam à mesa mais próxima da comida e do banheiro com os cotovelos alargados, postos sobre a mesa. Mesa a nós reservada durante o jantar de encerramento do evento. Mesa do cuidado delicado oferecido a nós: nós dos cuidados, das ajudas.

Gargalhadas saiam da mesa ocupada pelas promissoras outras, pelas "mulheres de cor" de Avtar Brah que faziam transbordar as fronteiras marrons. Fronteiras viventes. Risos sarcásticos de olhares cúmplices trocados por corpos que centralizam os caminhos das descidas e conhecem mapas com outras margens. Assim foram os olhares de Aibileen Clark para Minny Jackson. Duas das protagonistas do filme The Help: duas negras, gordas, trabalhadoras domésticas, pobres que mais do que terem de se submeter às leis de apartheid racial do estado do Mississipi na década de 1960, sentiam-se coagidas a atenderem ao rastreamento ordinário de seus corpos, ou melhor, seus fluídos, suas merdas, excrementos, ordinariamente controlados pelos usos e especificações de banheiros, papéis higiênicos, utensílios de cozinha, copos, toalhas... Artefatos conhecidos pelos controles femininos domésticos. The Help é um filme de mulheres, são elas protagonistas de um mundo que não passa pelos altos edifícios de Estado, assembleias, congressos, universidades privadas. Mas sim pelos acordos tácitos mantidos nos corredores de piso laminado, mármore e terra batida das cozinhas, das vielas, das varandas, das igrejas e das pequenezes cotidianas governamentais: delegacias, ônibus, prisões, hospitais. Em The Help, homens são coadjuvantes de processos estatais domesticados pelas relações postas nos quartos de dispensas. Trata-se disso, enfim, da ajuda, da ajudante, do cuidado e da cuidadora; da expertise em saber manter velados segredos públicos.

A mesa Brown da Women's Studies foi composta tão somente por mulheres marrons controladas em seus sotaques e acentos: outros excrementos poluidores. Cachos enredadores do 
poder de fazer falar o que deve ser cuidadosamente tácito. Carapinha das tramas de segredos que, todavia silenciados, podem afetar tramas de poder diárias, caseiras, íntimas, corporais. Eram destes nós que falavam nossos corpos mudos e risonhos postos estrategicamente na mesa perto da comida. Corpos negros fronteiriços, bárbaros conhecedores de expertises insolentes que poluem quimicamente os lisos cabelos louros de uma América do Norte distante das suas próprias calçadas hostis.

Foi indo embora desta mesa dos cuidados civilizatórios, levando acentos e embrolhos anotados em guardanapos, que assisti, desde aquela tela mínima de dentro do avião que descia pelo mapa oficial das rotas aviárias, The Help. Foi desde ali que me vi no espelho. Vi-me ao deparar com a cena da mãe que alisa os cachos da menina jornalista, recém-graduada, recém-chegada de Nova York a cidade de Jackson. A mãe a alisa na esperança de ela, enfim, fazer apaixonar um homem, encontrar um marido, casar certo, enquadrar-se, alisar, esbranquiçar.

As cenas, postadas na tela, de um Mississipi negro nas cozinhas, nas igrejas e nos ônibus em contraste com a branquidão dos auditórios que reuniam senhoras organizadoras de jantares beneficentes em prol das crianças da África, ironizavam em uma tessitura cruel com as trajetórias de Halli, seus filhos e sua esposa, com a subserviência de Gabriel e das copeiras mexicanas, com o lugar servil da ajuda que nossas peles marrons ocuparam nas cadeiras, mesas e jantares: microgeografia política da ordem que configura países, fronteira, acentos e corpos em "mundo" e "terceiro mundo".

Num riso sarcástico e com os olhos marejados, agradecia às ajudas recebidas.

Mas enfim, não iria mais embora daquele mundo terceiro. É disso que se trata fazer-se estranho: cruzar as margens e conhecer o entre, já diria Guimarães.

Cruzei algumas vezes mais com cenas mississipanas estendidas. Liguei, desde minha casa em um Santo André de ruas úmidas, a televisão, e ali estavam os mesmos cachos sendo alisados. Era o mesmo Mississipi congelado numa película gravada, mas o dia era outro e já não voava mais às cenas de minha infância. Desde lá, ia até a cadeira de um cabeleireiro negro, do mesmo bairro de periferia em que fora construída minha casa pelas mãos de uma mulher nordestina branca, minha sogra. O cabeleireiro insistia em me vender um programa de alisamento dizendo serem, meus cabelos crespos, uma maldição! A banalidade dos termos, a normalidade da fala me colocava, outra vez, no ponto estranho: enrolado. 
Voltava, contudo, por àquelas horas, desde outro norte, desde outros fusos. Havia passado dez dias por entre salas de aulas da Universidade Federal do Amazonas no campus de Benjamim Constant e em meio às fronteiras de Brasil, Colômbia e Peru nas cidades de Tabatinga, Letícia e Santa Rosa. Uma Amazônia profunda a que fui chamada, desde a brancura paulistana, para ministrar um curso: "Gênero e Violência: de Foucault a Butler", se chamava. Ali, eu ocuparia o púlpito.

A posição inversa da levada. Eu era a porta-voz de um francês branco gay e de uma gay norte-americana branca. Ao menos, diriam, eram pirofagistas. Mas a intenção ainda era a de incendiar uma mata. Lugares de enunciação, falaria Foucault.

Foi na primeira aula sobre "o tema" que Oscar, "aluno", ribeirinho, com a mesma idade que a minha, observou: "Deve ter sido mais fácil para Foucault se dizer gay? Tem haver com o que a senhora falou sobre lugar de enunciação, não é professora?’. Ser branco em Paris, protegido pelas salas de aula das L'écoles tinha mesmo seu lugar de enunciação. Mas Oscar não sabia que nem aquele havia sido suficientemente confortável para dizer-se gay. Foucault, por fim, só o fez nas fronteiras opostas ao sul do qual fui uma visita marrom. Foi entre os couros pretos de São Francisco, anos depois de deixar o extremo norte de seu mundo enevoado, que Foucault, como eu, encontrou outros lugares de enunciação.

Mas então, na terceira "aula", Patrícia balançou a cabeça veementemente. Ela, que exibia cicatrizes e tatuagens profundas pelo corpo magro de mulher divorciada, mãe arredada da família pela coragem de separar-se, aos dezenove anos, de um esposo violento, respondeu à Butler: "Eu quero sim o Estado! Se ela não quer, eu quero!”. E como o desejava! Uma professora universitária branca em Nova York (ou em São Paulo?) poderia até rejeitá-lo (será?), ela não!

A desobediência alargava a desordem da civilização subversiva, deslocava-a e fazia de minha caracolada, pelos tão lisos quanto à careca de Foucault. Ali, eu era o púlpito diante do riso sarcástico obscurecido pelo canto da boca vermelha. Lugares de enunciação. Minha brancura ressoava tonalidades professorais, hierarquicamente específicas.

$\mathrm{E}$ as mães de Mississipi, espelhadas nas minhas próprias, pedindo para alisar-me os enredos de tramas tão ferozes. Prefiro permanecer assim, longe da terceira margem, apanhando, batendo. Nessas parábolas fronteiriças que encontro pelas ruas que saem de minhas casas, meu espelho, meus corpos, meus cabelos enrolados: Não existe liso possível. Maldição! 


\section{BIBLIOGRAFIA}

ABU-LUGHOD, Lila. "Do Muslim Women Really Need Saving? Anthropological Reflections on Cultural Relativism and Its Others”. In: American Anthropologist, 2002, 104(3), pp. 783-790.

AKOTIRENE, Carla. O que é interseccionalidade? Rio de Janeiro: Editora Letramento, 2018.

ALEXANDER, Jacqui and MOHANTY, Chandra. "Cartographies of Knowledge and Power: Transnational Feminism as Radical Praxis". In: SWARR, Amanda Lock and NAGAR, Richa. Critical Transnational Feminist Praxis. State University of New York Press, 2010

BEAUVOIR, S. O segundo sexo: fatos e mitos. São Paulo: Difusão Européia do Livro, 1970. v. 1

BRAH, Avtar. Cartographies of diaspora. Contesting identities, Routledge, London, 1996.

CARDOSO, Cláudia Pons. Amefricanizando o feminismo: o pensamento de Lélia Gonzalez. Rev. Estud. Feministas. Florianópolis, v. 22, n. 3, p. 965-986, Dec. 2014. Disponível em http://www.scielo.br/scielo.php?script=sci arttext\&pid=S0104026X2014000300015\&lng=en\& nrm=iso Último acesso: 16 de setembro de 2018.

COLLINS, Patricia Hill. "Rasgos distintivos del pensamiento feminista negro". In: JABARDO, Mercedes(ed.). Feminismos Negros: Una ontologia. Madrid: Traficantes de Sueños, 2012.

CORRÊA, Mariza. Antropólogas \& Antropologia. Belo Horizonte: Editora da UFMG, 2003.

CRENSHAW, Kimberlé. "Documento para o encontro de especialistas em aspectos da discriminação racial relativos ao gênero". Revista Estudos Feministas, 2002.

DAS, Veena \& POOLE, Deborah. 'State and its margins: comparative ethnographies'. In: DAS, Veena \& POOLE, Deborah (eds.) Anthropology in the margins of the State. Oxford: James Currency, 2004, p. 3-33.

DAVIS, Angela. Mulher, Raça e Classe. São Paulo: Boitempo, 2017.

DAVIS, Angela. Estarão as prisões obsoletas? Rio de Janeiro: Difel, 2018.

FANON, Frantz. Pele negra, máscaras brancas. Rio de Janeiro: Editora Fator, 1983.

FANON, Frantz. Os condenados da terra. Juiz de Fora: Ed. UFJF, 2005.

FAUSTINO, Deivison Mendes. Frantz Fanon: Um revolucionário particularmente negro. São Paulo: Ciclo Contínuo Editorial, 2018. 
FASSIN, Didier. Humanitarian reason. A moral history of the present. Berkeley: University of California Press, 2011.

FOUCAULT, Michel. A história da sexualidade: A vontade de saber. Rio de Janeiro: Edições Graal, 1979.

FRIEDMANN, Georges. O trabalho em migalhas. São Paulo: Perspectiva, 1963.

GULLIAM, Angela; GILLIAM, Onik'a. "Negociando a subjetividade de mulata no Brasil”. Revista Estudos Feministas. Florianópolisv. 3, n. 2, p. 525, jan. 1995. ISSN 1806-9584. Disponível em: $<$ https://periodicos.ufsc.br/index.php/ref/article/view/16471>. Acesso em: 16 set. 2018.

GOLDMAN, Emma. "Women Suffrage". Anarchism and Other Essays. Second Revised Edition. New York \& London: Mother Earth Publishing Association, 1911. pp. 201-217

GOLDMAN, Emma. Living my Lyfe. New York: Penguin, 2006.

GONZALEZ, Lélia. “A categoria-cultural de amefricanidade”. In: Tempo Brasileiro. Rio de Janeiro, No. $92 / 93$ (jan./jun.). 1988a, p. 69-82

GONZALEZ, Lélia. "Nanny”. Humanidades, Brasília, (17): 23-25, 1988b

GREWAL, Inderpal. Transnational America. Durham and London: Duke University Press, 2005.

HARAWAY, Donna. "Gênero para um dicionário marxista: a política sexual de uma palavra". Cadernos Pagu, n²2, 2004

hooks, bell. We real cool: black man and masculinity. New York: Routledge, 2004

KUPER, Adam. Antropología y Antropólogos: La escuela Británica 1922-1972. Barcelona: Editorial Anagrama, 1973.

MAHLER, Sarah J.; PESSAR, Patricia R. "Gendered geographies of power: Analyzing gender across transnational spaces”. Identities, 2001, 7:4, p. 441-459.

MCCLINTOCK, Anne. Couro Imperial. Campinas: Editora da Unicamp, 2010.

MIGNOLO, Walter. "Are subaltern studies postmodern os postcolonial? The politics and sensibilities of geo-cultural locations". Disposition, v. 46, 1994, p. 45-73

MOHANTY, Chandra Talpade. 1984. "Under Western Eyes: Feminist Scholarship and Colonial Discourses”, Boundary 2 12(3), 1984, p.333-358

MONTEIRO, John. Negros da Terra: Índios e Bandeirantes nas Origens de São Paulo. São Paulo: Companhia das Letras, 2000. 
MOUTINHO, Laura. "Diferenças e desigualdades negociadas: raça, sexualidade e gênero em produções acadêmicas recentes”. In: Cadernos Pagu (42). Campinas: Janeiro-Junho, 2014, pp. 201248.

OLIVEIRA, João Pacheco de. O Nascimento do Brasil e Outros Ensaios: "Pacificação", Regime tutelar e Formação de alteridades. Rio de Janeiro: Contracapa, 2016.

PADOVANI, Natália Corazza. "Tráfico de mulheres nas portarias das prisões ou dispositivos de segurança e gênero nos processos de produção das 'classes perigosas'. Cadernos Pagu, v.51, 2017. Disponível em: $\quad$ http://www.scielo.br/scielo.php?script=sci arttext\&pid=S0104-

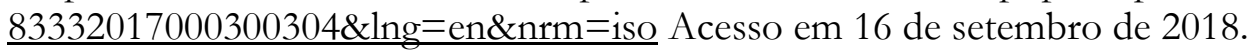

PADOVANI, Natália Corazza. "Detalhe ou dispositivo de gestão da vida? Breves reflexões sobre gênero e processos de estado". Boletim IBCCRIM, v.282, p.s/n - s/n, 2016 a.

PADOVANI, Natália Corazza. "Joias da família: trançando comandos entre irmãos". Revista Florestan, v.3, p.72 - 108, 2016.

PERROT, Michelle. História das mulheres no Ocidente (O século XX), v.5. Porto: Afrontamento; São Paulo: Ebradil, 1995.

PISCITELLI, Adriana. "Interseccionalidades, categorias de articulação e experiências de migrantes brasileiras". Sociedade e Cultura. Vol.11, n 2, 2008.

QUIJANO, Aníbal. Colonialidade do Poder, Eurocentrismo e América Latina. Buenos Aires, CLACSO, 2005.

SAID, Edward. O Orientalismo: O Oriente como invenção do Ocidente. São Paulo: Companhia das Letras, 2007.

SCOTT, Joan. "Gênero: uma categoria útil de análise histórica". Educação e realidade. Porto Alegre: vol 20, n², 1995.

SCOTT, Joan. A invisibilidade da experiência. Projeto História. Cultura e Trabalho. PUC-SP. São Paulo, n. 16, fevereiro 98, p. 297-327, 1998.

SPIVAK, Gayatri. Pode o subalterno falar? Belo Horizonte: Editora UFMG, 2010.

TRUTH, Sorjoner. "Convención de los Derechos de la Mujer". In: JABARDO, Mercedes(ed.). Feminismos Negros: Una ontologia. Madrid: Traficantes de Sueños, 2012.

WOOLF, Virginia. Um teto todo seu. São Paulo: Tordesilhas, 2014. 